INTERNACIONAL

\title{
El menoscabo sobre los derechos fundamentales de la etnia warao en Venezuela como consecuencia del VIH/sida y sus implicaciones en tiempos de pandemia
}

\author{
The undermining on the fundamental rights of the Warao ethnic group \\ in Venezuela as a consequence of HIV/AIDS \\ and its implications in times of pandemic
}

\section{Ángel Carmelo Prince Torres iD}

Instituto Universitario Pedagógico Monseñor Rafael Arias Blanco, Venezuela

\begin{abstract}
RESUMEN En este artículo se analizó el menoscabo de los derechos humanos del pueblo warao en la República Bolivariana de Venezuela, a raíz de la epidemia de VIH/sida que durante 2019 y 2020 ha sido confirmada entre ellos, también en el contexto de la pandemia por covid-19. El trabajo se desarrolló bajo investigación documental cualitativa, en la cual se revisaron doctrina, normas jurídicas y jurisprudencia para recabar la información necesaria. Se determinó que la etnia warao ha sido desatendida en la proliferación del VIH, lo que compromete sus derechos a la vida y salud, entre otros. También se observó que una causa para el abandono de estas personas se debe en la actualidad a la reasignación de recursos para abordar el combate al coronavirus, así que el Estado venezolano, como garante de los derechos fundamentales, está en el deber de corregir esta situación, pues es directamente responsable de lo ocurrido hasta ahora a estos indígenas.
\end{abstract}

PALABRAS CLAVE Derechos fundamentales, warao, sida, pandemia, pueblos indígenas.

ABSTRACT This paper analyzes the undermining on the human rights of the Warao people in the Bolivarian Republic of Venezuela, due to the AIDS epidemic existing during 2019 and 2020 among them, which was also confirmed on the context of the pandemic generated by Covid-19. This is a documental investigation with a qualitative approach, checking doctrine, law and jurisprudence to gather useful information. It was concluded that the Warao ethnic group has been abandoned in the middle of the generation of AIDS, compromising their rights to life, health, etc. It was also observed that these people were ignored because a lot of resources are being redirected to fight the 
coronavirus, so the Venezuelan State is responsible to correct this situation as a guardian of the fundamental rights.

KEYWORDS Fundamental rights, Warao, AIDS, pandemic, indigenous peoples.

\section{Introducción}

El concepto de vulnerabilidad se refiere a «algún tipo de amenaza, sean eventos de origen físico como sequías, terremotos, inundaciones o enfermedades, o amenazas antropogénicas como contaminación, accidentes, hambrunas o pérdida del empleo» (Ruiz Rivera, 2012: 64). Por ello, se asume que cuando un colectivo tomado como unidad de medida se encuentra en esta situación, es denominado grupo social vulnerable. Puede afirmarse que, vistos los eventos negativos de que pudieran resultar víctimas, los humanos allí incluidos se encuentran en especial situación de indefensión y debilidad jurídica.

En un principio, los derechos humanos se circunscribieron tradicionalmente a derechos de primera generación (civiles y políticos) y segunda generación (económicos, sociales y culturales), según los momentos históricos cuando fueron reconocidos. Sin embargo, con el transcurrir del tiempo, se han incorporado nuevas prerrogativas de acuerdo con los peligros que se han cernido sobre áreas concretas. Un tipo de derecho del que se habla desde hace algunos años es el que corresponde a los pueblos indígenas, ${ }^{1}$ pues representan conglomerados con culturas y prácticas singulares que, además, han sido históricamente mermados, por lo que pueden considerarse como grupos vulnerables.

Un núcleo social afectado por diferentes circunstancias que se indican más adelante es la etnia aborigen warao. Sobre ella, se aclara que «habitan los caños del delta del Orinoco y áreas adyacentes de la Guayana Esequiba y de los estados Bolívar, Monagas y Sucre [...] hoy día el delta del Orinoco en el extremo nororiental de Venezuela constituye el estado Delta Amacuro» (Tellería, 2008: 252), espectro territorial que corresponde a Venezuela.

El hecho de que los pueblos indígenas posean sus propias pautas normativas no quiere decir que se excluyan del sistema de derechos humanos generalmente aceptado a nivel internacional, con instrumentos como la Declaración Universal de los Derechos Humanos. Esto, porque los derechos fundamentales corresponden a toda la humanidad por tener esa característica, así que representan un reconocimiento natural de lo que a cada uno corresponde.

1. Los derechos indígenas constituyen un «sistema jurídico propio de un pueblo o grupo indígena que se ha ido construyendo a través de su práctica y su cosmovisión, no está escrito y se va transmitiendo de generación en generación» (Quintanilla, 2014: 89). 
Un gran problema que ha afectado a los warao durante los últimos años, y que ha sido reseñado por medios informativos, ha sido la proliferación del VIH/sida dentro del colectivo. Aún en 2020, dicha problemática persiste sin que, por lo visto, haya indicios de reconducción efectiva por parte del Estado venezolano. De hecho, científicamente se sostiene que «los recientes estudios de VIH/sida en población indígena amazónica indican una incidencia alarmante en diferentes países de Latinoamérica. Ese es el caso de los warao de Venezuela» (Rojas, 2019: 779). Tal situación no sólo representa una amenaza sobre los derechos humanos de los pueblos indígenas, sino que contraviene al espíritu de la protección a los derechos fundamentales, en especial en el sistema de Naciones Unidas.

La Carta de Naciones Unidas indica en su preámbulo que los conformantes de la fórmula se comprometen «a reafirmar la fe en los derechos fundamentales del hombre, en la dignidad y el valor de la persona humana». ${ }^{2} \mathrm{Al}$ ser una de las características de los derechos humanos su interdependencia e indivisibilidad, esto significa que al hablarse del aseguramiento de una vida digna, se incluirían derechos conexos como el de la vida, la salud, la integridad física y síquica, al trabajo y la educación, entre otros. Sin embargo, debido al fenómeno aquí planteado, surge el menoscabo de todo ese entramado, porque el daño a una prerrogativa implica un golpe a otras, cuanto más porque en el corriente año recae otra amenaza sobre las cabezas de las sociedades: la infección mundial por covid-19. ${ }^{3}$

Por lo ya planteado, esta investigación tuvo como propósito general examinar el menoscabo en los derechos fundamentales de la etnia warao en Venezuela como consecuencia del VIH/sida y sus implicaciones en tiempos de pandemia. A su vez, se plantearon los siguientes objetivos específicos: i) describir el entramado de los derechos humanos sobre los pueblos indígenas; ii) revisar la situación de los warao en cuanto a los estragos que el VIH/sida ha causado sobre ellos, en especial en razón de la pandemia que existe en 2020; iii) relacionar instrumentos jurídicos internacionales

2. Véase in extenso, con especial énfasis en el artículo 1, que propugna los propósitos de la Organización de Naciones Unidas, la Carta de Naciones Unidas, adoptada el 26 de junio de 1945.

3. El sida y covid-19 no son los únicos problemas de salud a los que se enfrenta la etnia, puesto que por la exposición intercultural y demás factores, se han desarrollado en sus miembros dolencias como sarampión, conjuntivitis, tos ferina, poliomielitis, difteria, cólera y paludismo, entre otras que parecieran haber llegado para quedarse. Alicia Moncada, «Los warao rodeados de epidemias que llegaron para quedarse», blog de Amnistía Internacional, 3 de julio de 2018, disponible en https://bit.ly/37sP5Jl. No obstante, debe acotarse que la red Médicos del Mundo ha tratado de colaborar con el mejoramiento de la situación de salud del grupo, a través de sistemas comunitarios interculturales para prevenir enfermedades, transporte de equipos de salud intercultural y fluvial (ESFI) para atención base y apertura a espacios de conversación entre autoridades locales y las comunidades warao, por lo que se recomienda leer: «Abordaje fluvial e intercultural con población etnia Warao en estado Delta Amacuro (Venezuela)», Médicos del Mundo, 15 de mayo de 2016, disponible en https://bit.ly/3h91sgV. 
y nacionales que dan protección a estos aborígenes en tan particulares circunstancias; y iv) discutir la responsabilidad del Estado venezolano sobre el abordaje de dicha problemática. De dicho modo, se inicia el desglose de este artículo.

\section{Metodología}

Este trabajo fue ensamblado bajo el enfoque de investigación cualitativa, que «se sustenta en evidencias que se orientan más hacia la descripción profunda del fenómeno con la finalidad de comprenderlo y explicarlo» (Sánchez, 2019: 104). En este caso, la evidencia se obtuvo para explicar el impacto que ha tenido el VIH/sida sobre la comunidad warao y sus implicaciones entre la diseminación actual de covid-19.

Para recabar las pruebas sobre este tópico, se siguió un esquema de pesquisa documental, el cual se basa en la revisión textos. Por ello, se recopiló información de artículos provenientes de medios noticiosos verificados, artículos de revistas científicas, libros, sitios web prestigiosos, normas jurídicas y jurisprudencia, entre otros. El examen de los datos se hizo con aplicación de la hermenéutica, el resumen analítico y el análisis crítico, a la vez que lo que resultara útil se recabó implementando la lectura en profundidad, el subrayado y el resumen. También se elaboraron los propósitos u objetivos, ordenándolos de acuerdo con su complejidad según la taxonomía de Bloom.

\section{Derechos humanos de los pueblos indígenas}

Los derechos humanos se adhieren a la cualidad del ser humano, de allí proviene su denominación, pues reconocen lo que corresponde naturalmente a hombres, mujeres, adolescentes y niños. Por eso, su naturaleza es declarativa y no constitutiva, pues estas directrices no representan concesiones - es decir, favores o gracias otorgadas por un Estado- que se hacen por medio de instrumentos jurídicos, sino que, cuando se escriben, sólo se reafirma su existencia. Estos derechos corresponden a sus titulares, independiente de los colectivos o subgrupos a los que pertenezcan. Por lo tanto, comportan una aplicación general para la humanidad, pero hay algunos de ellos que se encuentran especialmente vinculados con comunidades o ámbitos de particular fragilidad: es el caso de los derechos humanos de los pueblos indígenas.

En el ámbito internacional, «se reconoció que los pueblos indígenas son iguales a todos los demás pueblos, pero también se reconoce que son diferentes, y se les debe respeto» (García Medina, 2010: 33 ). ${ }^{4}$ Por ello, se ha reseñado el sistema de derechos

4. La discusión sobre los derechos humanos indígenas ya se ha hecho a través de textos y mecanismos como el «Convenio 169 de la OIT; la Declaración de Naciones Unidas sobre los Derechos de los Pueblos Indígenas de 2008; el Foro Permanente para Cuestiones Indígenas; dos declaraciones del Decenio Internacional de las Poblaciones Indígenas del Mundo (1995-2004 y 2005-2014); la Comisión y la Corte 
humanos de pueblos indígenas en las Naciones Unidas, ${ }^{5}$ aclarando que sus prerrogativas son: ${ }^{6}$

- Libre determinación, que es la capacidad para establecer su condición política y buscar desenvolvimiento cultural, social y económico.

- Derecho a sus tierras, territorios y recursos, incluso los que tradicionalmente les han pertenecido y son administrados por otros.

- Pautas adecuadas al núcleo de los derechos económicos, sociales y culturales reconocidos por Naciones Unidas, ${ }^{7}$ los cuales se refieren a la seguridad social, educación, salud, vivienda, empleo y, en general, una vida digna. Del mismo modo, con respecto a la protección a su cultura, se promueve el rechazo a la discriminación por motivos culturales, la no asimilación o supresión cultural, el derecho a la práctica y repotenciación de tradiciones, a la divulgación de convencionalismos, repatriación de restos mortales, dominio sobre el patrimonio cultural, conocimientos y expresiones, así como a la convivencia en una nación indígena, que es «un "lazo de parentesco individual", una forma de sociabilidad, un ligamen entre individuos que reconocen una serie de factores comunes en la estirpe» (Chalbaud Zerpa, 1995: 75).

- Derechos colectivos, pues corresponden a sujetos indígenas que conviven como un pueblo. Esto no implica una negación de derechos individuales.

- Igualdad y no discriminación en el disfrute de todos los derechos fundamentales, en aras de no estar sujetos a la segregación de la cual han sido víctimas históricamente.

- Derechos establecidos en tratados, acuerdos y demás arreglos entre Estados

Interamericana de Derechos Humanos [...]; la Declaración Americana sobre Derechos de los Pueblos Indígenas de 2016, y otros mecanismos regionales. Este sistema americano forma parte de lo que se conoce como sistema internacional de los derechos humanos», acota Quilaleo (2018).

5. «Los pueblos indígenas y el sistema de derechos humanos de las Naciones Unidas», Oficina del Alto Comisionado de Naciones Unidas para los Derechos Humanos, folleto informativo 9/Rev.2, 2013, disponible en https://bit.ly/3nwiqYC.

6. Véase in extenso el texto de la Asamblea General de Naciones Unidas, Declaración de las Naciones Unidas sobre los Derechos de los Pueblos Indígenas, adoptada el 13 de septiembre 2007.

7. Se desprenden, entre otros, de la Organización Internacional del Trabajo, Convenio 169 sobre Pueblos Indígenas y Tribales en Países Independientes, adoptado el 27 de junio de 1989; Naciones Unidas, Pacto Internacional de Derechos Económicos, Sociales y Culturales, adoptado el 16 de diciembre de 1966; Naciones Unidas, Declaración Universal de Derechos Humanos, adoptada el 10 de diciembre de 1948; así como las interpretaciones de esta especie de prerrogativas en Comité de Derechos Humanos, Observación General 23, de 1994, sobre el derecho de las minorías; y Comité de Derechos Económicos, Sociales y Culturales, Observación General 21, de 2009. 
y las comunidades indígenas, pues en la Declaración indicada se concibe que tales convenios sean respetados por estos entes y sus sucesores.

Aunque la Declaración sobre Derechos de los Pueblos Indígenas no tiene carácter vinculante per se, sí constituye una reafirmación de principios contenidos en instrumentos internacionales obligatorios. Este texto es un cuerpo de soft law, ${ }^{8}$ por lo que puede usarse como referente para establecer responsabilidades de derecho.

Ahora bien, respecto específicamente del derecho a la salud en los pueblos indígenas, el cual se relaciona directamente con este artículo, el Convenio 169 de la OIT sobre Pueblos Indígenas y Tribales en Países Independientes establece en su artículo 24.1 que «los regímenes de seguridad social deberán extenderse progresivamente a los pueblos interesados y aplicárseles sin discriminación alguna». En concordancia con ello, el artículo 25.1 sostiene que «los Gobiernos deberán velar por que se pongan a disposición de los pueblos interesados servicios de salud adecuados o proporcionar a dichos pueblos los medios que les permitan organizar y prestar tales servicios bajo su propia responsabilidad y control».

Entonces, según lo anterior, existe un fundamento jurídico internacional para afirmar que las etnias indígenas cuentan con un blindaje en cuanto a los deberes estatales suscritos por los países para proteger su integridad física, pues, como indica Amoroz (2011), el Estado es protagonista en garantía, guarda, aseguramiento e impulso de esta prerrogativa a través de sus compromisos interestatales. Todo esto se encuentra en relación con el artículo 18 de la Declaración Americana sobre los Derechos de los Pueblos Indígenas cuando estatuye que:

- Los pueblos indígenas tienen derecho en forma colectiva e individual al disfrute del más alto nivel posible de salud física, mental y espiritual.

- Los pueblos indígenas tienen derecho a sus propios sistemas y prácticas de salud, así como al uso y la protección de las plantas, animales, minerales de interés vital, $y$ otros recursos naturales de uso medicinal en sus tierras y territorios ancestrales.

- Los Estados tomarán medidas para prevenir y prohibir que los pueblos y las personas indígenas sean objeto de programas de investigación, experimentación biológica o médica, así como la esterilización sin su consentimiento previo libre e informado. Asimismo, los pueblos y las personas indígenas tienen derecho, según sea el caso, al acceso a sus propios datos, expedientes médicos

8. A pesar de que la Declaración no es de carácter obligatorio, puede dar nacimiento a consideraciones de tipo jurídico, por haber sido elaborada en una organización internacional, bajo votación y con anuencia de la mayoría de sus miembros. Así, es utilizable en forma interpretativa o referencial en la aplicación de la ley y progresivamente podría generar la obligatoriedad. 
y documentos de investigación conducidos por personas e instituciones públicas o privadas.

- Los pueblos indígenas tienen derecho a utilizar, sin discriminación alguna, todas las instituciones y servicios de salud y atención médica accesibles a la población en general. Los Estados en consulta y coordinación con los pueblos indígenas promoverán sistemas o prácticas interculturales en los servicios médicos y sanitarios que se provean en las comunidades indígenas, incluyendo la formación de técnicos y profesionales indígenas de salud.

- Los Estados garantizarán el ejercicio efectivo de los derechos contenidos en este artículo.

En Venezuela, todo este grupo de derechos se encuentra protegido en la Constitución de la República. ${ }^{9}$ También por vía legislativa se ha desarrollado el marco de esos principios constitucionales, destacando:

Ley de Demarcación y Garantía del Hábitat y Tierras de los Pueblos Indígenas (2001); Ley Orgánica de Pueblos y Comunidades Indígenas (2005); Ley de Idiomas Indígenas (2008); Ley de Educación Indígena (2013); ratificación en 2001 del Convenio 169 sobre Pueblos Indígenas y Tribales de la Organización Internacional del Trabajo, como lo más relevante (Orellano, 2016: 118).

Así, se han elaborado bases para la protección sobre diversos derechos de los pueblos indígenas. Sin embargo, no siempre han sido efectivas, como demuestra la disminución poblacional de los warao por la proliferación de VIH/sida en sus comunidades, que son más vulnerables durante la pandemia.

\section{Los warao y el VIH/sida: Implicancias en pandemia y su discusión}

Constantemente ha sido reseñada la situación del pueblo warao y el impacto que ha tenido el VIH/sida sobre él. Es esencial determinar aquí el alcance sobre las acciones de la gobernanza para proteger de manera efectiva a su población, pues si se ejecutan las medidas necesarias a tiempo, puede evitarse la muerte de cualquier persona contagiada por este retrovirus.

La enfermedad no tiene por qué mermar de manera significativa un segmento poblacional si se acciona con provisión de métodos anticonceptivos como el condón, aplicación de tratamientos preexposición y profilaxis posexposición, entre otras. También es crucial la correcta atención médica y suministro de medicamentos re-

9. Véase in extenso el título 3, «De los Derechos Humanos y Garantías, y de los Deberes», con especial referencia al capítulo 8, de los derechos de los pueblos indígenas, artículos 119 a 126, en el que se resguarda su integridad cultural, organización sociopolítica, económica e incluso territorial en la Constitución de la República Bolivariana de Venezuela. 
trovirales que impiden la replicación viral, porque, aunque muchos lo desconocen, el virus de inmunodeficiencia humana y el síndrome de inmunodeficiencia humana son diferentes: el primero es el agente, y el segundo es la dolencia. Quien tenga VIH no necesariamente desarrolla sida. ${ }^{10}$

Como referencia a lo que ocurre con los warao, se indica que «llevan conviviendo con el virus cerca de quince años, que se ha encontrado con una cepa más agresiva que desarrolla los síntomas en cinco años y que hay comunidades ya desaparecidas, arrasadas por el sida» (Bernal y otros, 2018: 162). Este hecho constituye una notoria vulneración de derechos humanos, pero lo peor es que la afirmación se refuerza con estos datos:

El Instituto Venezolano de Investigaciones Científicas y el Instituto de Biomedicina de la Universidad Central de Venezuela, realizaron investigaciones en 26 comunidades warao del delta del Orinoco, y encontraron la presencia del virus en el 9,55\% de los habitantes de ocho comunidades, lo cual representa una prevalencia altísima tomando en cuenta que, en el país, es del 0,56\%. La comunidad más afectada es la usidu, con el 21,6\% (Muñoz, Ponce y Stival, 2017: 541).

Esta problemática se ha reiterado con el tiempo y su testimonio son investigaciones periodísticas que acotan que el VIH/sida socava la existencia de los warao, lo cual se agrava por la crisis del sistema de salud venezolano, la falta de distribución de preservativos por parte del Gobierno y la deficiencia de medicinas. ${ }^{11}$ Del mismo modo, se enfatiza que el desabastecimiento de hasta 24 antirretrovirales ha tenido incidencia directa en el contagio que prevalece en hombres que conviven en comunidades donde hasta el $35 \%$ de ellos lo padece. ${ }^{12}$ Debido a la persistencia del fenómeno, en 2019 Naciones Unidas ha tenido que actuar con la distribución de retrovirales y jornadas de descarte viral, especialmente entre mujeres warao. ${ }^{13}$

Dicho asunto se ha convertido en un factor que, sumado a la proliferación de la covid-19, ha golpeado a la etnia, ya que coadyuva a migración forzada de miles de sus miembros hacia Brasil en el marco de la emergencia humanitaria venezolana. Incluso, en mayo 2020 se registraban, de acuerdo con la Agencia de Naciones Unidas para los Refugiados (ACNUR), unos 3.300 waraos ya movilizados a suelo brasileño, que

10. «Glosario», Clinical Info HIV.org, Departamento de Salud y Servicios Humanos de Estados Unidos, 2018, disponible en https://bit.ly/38aUC6s.

11. Véase a Kirk Semple, «En Venezuela, el aumento del sida amenaza a toda una población indígena». The New York Times, 7 de mayo 2018, disponible en https://nyti.ms/37rdHBW.

12. Karenina Velandia, “"Imaginar el futuro de la tribu da miedo": La epidemia de VIH diezma a una etnia indígena latinoamericana», $B B C$ Mundo, 11 de enero 2018, disponible en https://bbc.in/37tvtVh.

13. «ONUSIDA Venezuela impulsa abordaje integral de atención, prevención y diagnóstico de VIH/ sida en comunidades indígenas warao», ONUSIDA, 12 de noviembre de 2020, disponible en https://bit. ly/3gVop75. 
no contaban en su país con infraestructura sanitaria para abordar los contagios por coronavirus. Los curanderos warao wisidatu equiparan al sida y covid-19 como jebu o enfermedades sobre muchos, originadas con «un viento malo». También es grave la reseña de que el Gobierno nacional no se ocupa del asunto desde antes del confinamiento, pues los seropositivos no obtienen tratamientos integrales y gran parte ha fallecido, atestiguando que no existe una sólida colaboración intercultural en cuanto a salud para abordar la problemática. Desde octubre 2019 se determinó, gracias a ONUSIDA, que hay prevalencia de 2,69\% en comunidades como Mukaro, San Francisco de Guayo y Jobure de Guayo. ${ }^{14}$

Como nota complementaria, debe destacarse que ha sido plasmado en medios de comunicación que incluso la Comisión Interamericana de Derechos Humanos (CIDH) se pronunció en la plataforma digital Twitter solicitando apoyo sanitario a los warao porque no se han visto cubiertas las necesidades generadas en ellos como consecuencia de la pandemia. ${ }^{15}$ Esto se ve porque, en líneas generales, hasta el 10 de noviembre de 2020, se reportaron oficialmente en Venezuela 95.149 casos de infectados con 830 fallecidos. ${ }^{16} \mathrm{El}$ virus ha afectado al país por medio del establecimiento de medidas de confinamiento en las cuales se provee una semana de flexibilización para actividades comerciales y otra en la cual se prohíben salvo a determinados sectores, lo cual ha golpeado a la ya malograda economía del país sudamericano, pues incluso se limita la circulación de personas en la calle después de determinadas horas.

Las medidas que se han tomado para evitar la propagación del virus incluyen cierre de fronteras, obligatoriedad en el uso de cubrebocas, bloqueo de vuelos - salvo los de carácter humanitario- e incluso se ha reseñado el despliegue de fuerzas de seguridad para intimidar a quienes cuestionen las medidas gubernamentales para afrontar a la enfermedad, aun cuando sean médicos y otros expertos, amén de recluir a muchos de quienes llegan desde el extranjero en centros improvisados, como hoteles incautados, en condiciones reprochables de hacinamiento y con vigilancia militar, mientras se aplican tratamientos y pruebas a quienes allí se encuentren. Todo ello se suma a un sistema sanitario colapsado y recursos mermados en función de la debacle financiera del país. ${ }^{17}$

14. Shari Avendaño, María Fermín y Edgar López, «La pandemia no detiene el éxodo de los waraos (II)», Efecto Cocuyo, 2 de agosto 2020, disponible en https://bit.ly/3nwpnJc.

15. Alexander Medina, «La CIDH se pronuncia sobre la situación del pueblo warao ante el covid-19», Radio Fe y Alegría, 9 de junio de 2020, disponible en https://bit.ly/3peOPnl.

16. «Coronavirus hoy en Venezuela: Cuántos casos se registran al 10 de noviembre», La Nación, 10 de noviembre de 2020, disponible en https://bit.ly/3pePncT.

17. Sobre esto, véase in extenso el escrito de Anatoly Kurmanaev, Isayen Herrera y Sheyla Urdaneta, «Venezuela enfrenta al coronavirus con la fuerza de sus agentes de seguridad», The New York Times, 19 de agosto de 2020, disponible en https://nyti.ms/38cHxcO. 
Aparte, específicamente con respecto al grupo indígena aquí tratado, se indica que en zonas urbanas y rurales el coronavirus ha afectado el acceso a alimentos, impulsando la presencia de foráneos en sus territorios y también en esta época se ha potenciado la contaminación de las aguas de las cuales dependen, lo cual es un factor de riesgo enorme si tenemos en cuenta que la higiene es esencial para el combate de las enfermedades y se necesita en aras de canalizarla. La presencia de personas ajenas a la etnia dentro de sus entornos ha constituido un peligro, en vista de que con ello aumentan las posibilidades de diseminación del virus SARS-CoV-2 y, por lo tanto, la activación de contagios. ${ }^{18}$ Incluso, este fenómeno ha ocasionado que la pacífica comunidad warao haya organizado protestas, porque percibe desprotección frente a las acciones emprendidas por el Estado para resguardarla del coronavirus. ${ }^{19}$

Asimismo, ACNUR manifiesta preocupación por los desplazados warao en Brasil, pues afrontan dificultades para luchar contra el coronavirus por motivos de documentos y saneamiento, falta de jabón, agua potable y nutrición adecuada. ${ }^{20}$ Incluso, ya se ha reportado el fallecimiento en Brasil de una aborigen de la etnia, originaria del estado venezolano Delta Amacuro, que se encontraba allí como refugiada y sucumbió ante la covid-19, ${ }^{21}$ con lo cual se denotan los efectos de la enfermedad sobre los miembros del conglomerado, que no escapa a la realidad mundial. Ya que una de las causas del traslado de esta etnia ha sido la incidencia de VIH/sida, se observa una relación directa entre esto y que los indígenas pasen por este trance en medio de la pandemia, pues para dar otra estocada, a los pacientes con dicha condición los afecta el problema que recae sobre los seropositivos en América Latina: se han reasignado recursos normalmente destinados a ellos para combatir al coronavirus. ${ }^{22}$

En Iberoamérica, «la mitad de las personas con VIH tienen dificultades para obtener su tratamiento antirretroviral durante la pandemia $»^{23}$ y esta es otra arista del problema que potencialmente afecta a los warao, pues se desenvuelven en este espacio territorial. La relevancia jurídica de todo lo aquí reseñado estriba en que en

18. «CIDH pide atención sanitaria para indígenas en Venezuela», Diario Las Américas, 10 de junio de 2020, disponible en https://bit.ly/3mvHygQ.

19. «CIDH urge a Venezuela a "brindar atención sanitaria" a los indígenas warao frente a la pandemia», Europa Press, 10 de junio de 2020, disponible en https://bit.ly/3nHGU1v.

20. "Refugiados indígenas luchan contra el coronavirus en América Latina», Oficina del Alto Comisionado de las Naciones Unidas para los Refugiados, 19 de mayo de 2020, disponible en https://bit. ly/2WoxWtZ.

21. Jhoalys Siverio, «Refugiada warao de Delta Amacuro muere de covid-19 el hospital de Boa Vista», Correo del Caroní, 11 de mayo de 2020, disponible en https://bit.ly/37v4rg4.

22. Carlos Salinas Maldonado, «La lucha por sobrevivir al VIH en Latinoamérica durante la pandemia del coronavirus», El País, 23 de mayo de 2020, disponible en https://bit.ly/37vG16t.

23. "La mitad de los latinoamericanos con VIH tienen problemas para conseguir antirretrovirales», Noticias ONU, 24 de junio de 2020, disponible en https://bit.ly/37uzZiw. 
Venezuela podría usarse para valorar la responsabilidad del Estado en un eventual proceso judicial, pues allí existe un elemento probatorio: el hecho comunicacional.

Esta prueba es notoria, de acuerdo con la jurisprudencia venezolana, porque resulta de la difusión masiva por medios de comunicación, pero también debe reunir ciertas condiciones: i) ser un hecho, no una opinión o testimonio; ii) tiene que difundirse paralelamente por diversos canales de comunicación escritos, radiales o audiovisuales; iii) el hecho no puede ser dudoso, sujeto a rectificación o presunción de falsedad; y iv) la contemporaneidad del hecho para la fecha del proceso o emisión de la decisión. ${ }^{24}$ Aquí el hecho es la merma del pueblo warao por la inacción ante el $\mathrm{VIH} /$ sida por parte del Gobierno, lo cual ha sido persistente a través de los años, avalado por informes científicos y reseñado por múltiples medios durante los mismos ámbitos temporales.

Para este autor, es evidente que existe consecuencia directa entre los estragos del sida sobre los warao y el abordaje inadecuado que sobre el tema ha hecho la gobernanza, debido a que estudios y hechos reseñados atestiguan un compendio de vulneraciones a derechos humanos recogidos en textos internacionales, que incluso son resguardados en la Constitución venezolana. Entre los instrumentos universales relativos a derechos fundamentales, la Declaración Universal de los Derechos Humanos considera en su preámbulo «el reconocimiento de la dignidad intrínseca y de los derechos iguales e inalienables de todos los miembros de la familia humana» (Bou Franch, 2003: 45), así que cuando se desatiende a los pueblos indígenas, se desatiende a ese mandato.

Al no tratar debidamente a los pacientes de la etnia con $\mathrm{VIH} /$ sida, ni procurarse mecanismos para impedir la proliferación del virus en pandemia cuando ha disminuido la asignación de esfuerzos para esta causa, en aras de reconducir insumos para combatir al coronavirus, ha de recordarse que «la responsabilidad del Estado por violación a los derechos humanos se vincula con [...] que no debe efectuar normas que puedan llegar a restringir o destruir derechos fundamentales, como tampoco debe actuar en clara violación a los parámetros constitucionales» (Maraniello, 2014: 146). A esto cabría agregar que la relación directa de causalidad en la violación de derechos humanos también estriba del incumplimiento de deberes adquiridos en convenios internacionales, amén de la inacción, omisión o negligencia para asegurarlos.

No sería temerario señalar que el Estado venezolano ha incumplido en forma reiterada con la protección a derechos contemplados en la Declaración Universal de los Derechos Humanos: a la vida; satisfacción de los derechos económicos, sociales y culturales; trabajo - pues personas con dificultades de salud en ocasiones no podrían ejercer sus labores, ya limitadas por confinamiento-; una vida digna en que se ga-

24. Sentencia del caso Acción de amparo de Coronel OSH con Tribunal Instructor de la Corte Marcial, Sala Constitucional del Tribunal Supremo de Justicia de Venezuela, 15 de marzo de 2000. 
rantice bienestar y salud; y la educación — para personas comprometidas físicamente por sida, que por ello no puedan cumplir con sus compromisos académicos-. También se contraría al derecho al establecimiento de un orden social en que se garanticen derechos y libertades de la Declaración. ${ }^{25}$

En cuanto al Pacto Internacional de Derechos Civiles y Políticos, se socavan los derechos a la vida, protección familiar, protección a los niños, protección por igualdad ante la ley y sin discriminaciones, e incluso en una interpretación extensiva, se vulnera la no sujeción a tratos inhumanos, ${ }^{26}$ que doctrinalmente se asumen como aquellos que inciden contra la naturaleza humana, su dignidad e integridad (Martínez, 2011), las cuales se ven bombardeadas por la desatención a la emergencia de salud warao, porque los condena a una vida de suplicios. Aparte, habría que incluir el menoscabo al deber estatal de mantener elevados patrones de salud personal física y mental, con aseguramiento de medidas para prevenir y tratar enfermedades, lo cual se incluye en el Pacto Internacional de Derechos Económicos, Sociales y Culturales (artículo 12.2). ${ }^{27}$

Con respecto a instrumentos jurídicos regionales, la responsabilidad estatal se entraña por vulneración de instrumentos americanos (debido al espacio dentro del cual se suscita el fenómeno) en cuanto a derechos como la vida, mantenimiento de la salud y sistemas sanitarios ${ }^{28} \mathrm{e}$ incluso a la integridad física, moral y síquica, que se erosiona si no se proveen cuidados médicos necesarios a quienes los requieran. ${ }^{29}$ La Constitución venezolana también establece la protección sobre estas cuestiones e indica en su artículo 122 que «los pueblos indígenas tienen derecho a una salud integral que considere sus prácticas y culturas». Entonces, resulta inadmisible que el Gobierno no asuma sus compromisos ante esta tragedia, cuanto más porque, en cuanto a jurisprudencia, se ha reconocido la protección a los pacientes con VIH/ sida. ${ }^{30}$

25. Véanse los artículos 3, 22, 23, 2526.1 y 28 de la Declaración.

26. Véanse los artículos 6.1, 23, 24, 26 y 7, respectivamente, del Pacto.

27. Aquí también se reconoce el derecho a trabajar (artículo 6) y el derecho a la educación (artículo 13), los cuales, como se indicó, se afectan de forma conexa.

28. Artículos 1 y 11 de la Declaración Americana de los Derechos y Deberes del Hombre.

29. Sobre ello, véanse los artículos 4 (derecho a la vida) y 5 de la Convención Americana sobre Derechos Humanos (Pacto de San José de Costa Rica).

30. Véase in extenso la sentencia del caso Acción de amparo de López Glenda y otros con Instituto Venezolano de los Seguros Sociales (IVSS), Sala Constitucional del Tribunal Supremo de Justicia, 2 de diciembre 2002. En ella se determina que al omitir el IVSS la provisión efectiva de medicamentos a los pacientes con VIH/sida, existe violación del derecho a la salud y a la vida, igual que un menoscabo del derecho a beneficiarse de la ciencia, la tecnología y seguridad social previstas constitucionalmente y en convenios internacionales de derechos humanos. También se ratificó a la Sala Constitucional del Tribunal Supremo de Justicia, Acción de amparo de Loreto Tabares y otros con IVSS, sentencia del 6 de abril de 2001. 
El llamado a estos instrumentos no es exclusivo ni excluyente, porque no representa negación de otros textos jurídicos que pudieran aplicarse e interpretarse para determinar la responsabilidad del Estado en esta trama. Todo ello constituye un sistema que, estudiado de forma óptima, puede dar paso al impulso de mecanismos de derecho internos y externos para resguardar a los warao en estas circunstancias, y cuyo desglose, si bien no es tópico de esta investigación, podría ser tema de futuros artículos científicos.

\section{Conclusiones}

En virtud de los objetivos planteados dentro de este trabajo, puede concluirse que el pueblo warao, al ser afectado por el VIH/sida en medio de la pandemia por covid-19, tiene doble vulnerabilidad: por razones de salud y porque representa un grupo minoritario históricamente comprometido.

Los derechos de los pueblos indígenas no consideran la exclusión de derechos fundamentales generales, pero deben tomarse de manera concretizada, debido a los peligros que enfrentan sus conformantes.

La disminución de la población warao ha sido considerable en vista de la epidemia de VIH/sida que los aqueja, y esto se potencia en tiempos de pandemia, pues los sistemas sanitarios que deberían atenderlos están desbordados para atender la emergencia del coronavirus, aunque también obedece a la inacción del Estado venezolano sobre esta incidencia.

Existen instrumentos jurídicos nacionales e internacionales que contemplan la protección especial de los pueblos indígenas en esta situación, pero no es garantía de que su aplicación durante 2019 y 2020 haya sido efectiva.

El Estado venezolano y su gobernanza son directamente responsables por menoscabo en los derechos humanos de los warao con VIH, pues por lo observado, no ha respetado acuerdos que ha suscrito a nivel internacional en su texto constitucional como contrato social y su sistema de derecho interno, lo cual es una grave muestra de negligencia en marco de una rectoría que debe propugnar valores democráticos y de bien común.

Resulta triste ver que guardianes de la cultura originaria de América Latina sean ignorados, porque esto representa una amenaza contra el legado que ancestralmente han llevado en sus manos. Es necesario respetar las normas jurídicas que resguardan a los seres humanos, en especial a los warao, porque de nada vale tener la regla escrita o consuetudinaria si de forma persistente se invisibiliza o violenta contraponiéndose a postulados de justicia social. Por ello, todo Estado tiene que tomar seriedad en sus obligaciones para promover la máxima de Ulpiano: Justitia est constans et perpetua voluntas ius suum cuique tribuiendi. 


\section{Referencias}

Amoroz, Iliana (2011). «El derecho a la salud en comunidades indígenas del estado de Chiapas». Revista Pueblos y Fronteras Digital, 6 (11): 8-37. DOI: 10.22201/ cimsur.18704115e.2011.11.133.

Bernal, Daniel, Rubén Muñoz, Patricia Ponce y Matías Stival (2018). «La epidemia de VIH en pueblos originarios de México: Panorama nacional y un estudio de caso etnográfico en los Altos de Chiapas». Entre Diversidades, 10: 155-187. Disponible en https://bit.ly/2Wtlhpq.

Bou Franch, Valentín (2003). Derechos humanos. Valencia: Tirant lo Blanch.

Chalbaud Zerpa, Reinaldo (1995). Estado y política. Caracas: Mobil-Libros.

García Medina, Carlos (2010). «Retos de los derechos humanos en el siglo XXI: Los pueblos indígenas». Sapiens, 11 (1): 31-46. Disponible en https://bit.ly/2KzKs7g.

Maraniello, Patricio (2014). «Los derechos humanos y la responsabilidad del Estado». Criterio Jurídico, 13 (2): 127-148. Disponible en https://bit.ly/37twZGP.

MartíneZ, Narciso (2011). «Trato inhumano o degradante». En Carlos Romeo Casabona (director), Enciclopedia de bioderecho y bioética. Madrid: Comares. Disponible en https://bit.ly/3h1mrBT.

Muñoz, Rubén, Patricia Ponce y Matías Stival (2017). «Pueblos indígenas, VIH y políticas públicas en Latinoamérica: Una exploración en el panorama actual de la prevalencia epidemiológica, la prevención, la atención y el seguimiento oportuno». Salud Colectiva, 13 (3): 537-554. DOI: 10.18294/sc.2017.1120.

Orellano, Jorge (2016). «Derechos de los pueblos indígenas en Venezuela y el problema del reconocimiento». Anthropologica, 34 (36): 113-148. DOI: 10.18800/ anthropologica.201601.005.

Quilaleo, Fernando (2018). «La implementación del Convenio 169 de la OIT en Chile: La paradoja de los derechos indígenas». Anuario de Derechos Humanos, 14: 141-153. DOI: 10.5354/0718-2279.2018.49199.

Quintanilla, Estenka (2014). «Derecho internacional de los derechos humanos de los pueblos indígenas». Revista Jurídica Derecho, 1 (1): 87-94. Disponible en https://bit.ly/3mx4X1E.

Rojas, Ximena (2019). «Entre játa y waweamu: VIH/sida en las comunidades awajún de la Amazonía peruana». Mana, 25 (3): 777-808. DOI: 10.1590/1678-49442019v25n3p777.

Ruiz Rivera, Naxhelli (2012). «La definición y medición de la vulnerabilidad social: Un enfoque normativo». Investigaciones Geográficas, 77: 63-74. Disponible en http://ref.scielo.org/q3xyyr.

SÁncheZ, Fabio (2019). «Fundamentos epistémicos de la investigación cualitativa y cuantitativa: Consensos y disensos». Revista Digital Investigación y Docencia, 13 (1): 101-122. DOI: 10.19083/ridu.2019.644. 
Tellería, Nelson (2008). «Caracterización socio-educativa de una comunidad Warao: Estado Delta Amacuro». Investigación y Postgrado, 23 (1):249-264. Disponible en https://bit.ly/2WrN5dR.

\section{Sobre el autor}

Ángel Carmelo Prince Torres es abogado egresado de la Universidad Fermín Toro, Venezuela. Técnico superior universitario en Educación Comercial/Profesor en Educación Comercial, egresado del Instituto Universitario Pedagógico «Monseñor Rafael Arias Blanco», Venezuela. Magíster en Derecho Administrativo y Tributario, así como Máster Universitario en Derecho Internacional por la Universidad Complutense de Madrid, España. Doctor en Ciencias de la Educación de la Universidad Fermín Toro. Docente de pregrado y postgrado de la Universidad Fermín Toro, Universidad Centroccidental Lisandro Alvarado e Instituto Universitario Pedagógico Monseñor Rafael Arias Blanco, Venezuela. Su correo electrónico es arbqto@gmail. com. (D) https://orcid.org/0000-0002-0059-7797. 
El Anuario de Derechos Humanos es una publicación semestral de referencia y consulta en materia de derechos humanos y campos afines. Busca ser un espacio de discusión de los temas centrales en el ámbito nacional e internacional sobre derechos humanos. Es publicado desde 2005 por el Centro de Derechos Humanos de la Facultad de Derecho de la Universidad de Chile.

\author{
EDITORA \\ Claudia Iriarte Rivas \\ ciriarter@derecho.uchile.cl \\ SITIO WEB \\ anuariocdh.uchile.cl \\ CORREO ELECTRÓNICO \\ anuario-cdh@derecho.uchile.cl \\ LICENCIA DE ESTE ARTÍCULO \\ Creative Commons Atribución Compartir Igual 4.o Internacional
}

\author{
\% \\ La edición de textos, el diseño editorial \\ y la conversión a formatos electrónicos de este artículo \\ estuvieron a cargo de Tipográfica \\ (www.tipografica.io)
}

